\title{
Avaliação técnica e econômica da produção de milho em diferentes lâminas de irrigação
}

Luis Humberto Bahú Ben, Ana Rita Costenaro Parizi, Fátima Cibele Soares, Anderson Crestani Pereira, Ricardo Benetti Rosso, Leonita Beatriz Girardi, Marcos Vinicius Loregian

https://doi.org/10.4322/mp.978-65-991393-7-6.c4

\section{Resumo}

Com o risco de deficiência hídrica na produção de milho a utilização de sistemas de irrigação está em ascensão, assim a análise técnica, econômica e financeira de seu uso deve ser realizada para minimizar os custos, aumentar o lucro e auxiliar aos produtores na tomada de decisão. Portanto objetivou-se neste trabalho verificar a influência de lâminas de irrigação suplementar na viabilidade técnica, econômica e financeira da produção de milho safrinha para três cenários de preço de venda de produto. Conduziu-se dois experimentos de campo em um Delineamento de Blocos ao Acaso no Instituto Federal Farroupilha - Campus de Alegrete/RS, no período de fevereiro a junho de 2012 e 2013, com o híbrido de milho AS 1551 de ciclo precoce. Utilizou-se um sistema de irrigação por aspersão convencional, sendo o manejo realizado pelo cálculo da evapotranspiração da cultura (ETc). Os tratamentos em 2012 foram a Reposição de: T1 - 50\%, T2 - 65\%, T3 - 75\%, T4 - 85\% e T5 - 100\% da ETc; para 2013 foram: T0 - sem irrigação; T2 - 45\%; T3 - 72\%; T4 - 83\% e T5 - Reposição de $100 \%$ da ETc. Analisou-se a produtividade de grãos $\left(\mathrm{kg} \mathrm{ha}^{-1}\right)$, o custo de produção, a receita líquida, o Valor Presente Líquido e a Razão Benefício/Custo. Os custos com irrigação foram obtidos através de levantamentos e dimensionamento de sistemas de irrigação a nível de produtor e as receitas obtidas com três cenários de venda de produto, sendo: CP - USD 0,128; CM - USD 0,177 e CO - USD 0,226 por kg de grãos. Foram necessários a aplicação de 242 e $111 \mathrm{~mm}$ de água no T5 para os anos 2012 e 2013, respectivamente. O aumento da lâmina de irrigação suplementar proporcionou o aumento da produtividade de grãos do milho, com máximo valor de $14624,6 \mathrm{~kg} \mathrm{ha}^{-1}$ (experimento 1) e $13809,04 \mathrm{~kg} \mathrm{ha}^{-1}$ (experimento 2). A receita líquida variou entre o mínimo de USD -46,14 (CP e T0) e máxima de USD 2216,50 (CO e T5), sendo que no cenário de venda $\mathrm{CP}$, a lâmina sem irrigação foi negativa. Concluiu-se que o milho safrinha apresenta incremento de produtividade de grãos quando submetido a irrigação suplementar. Os custos de produção de milho irrigado aumentam entre $39,5 \%$ e $52,3 \%$ em relação ao cultivo de sequeiro. Lâminas de irrigação entre $85 \%$ e $100 \%$ da ETc proporcionam os maiores valores de Receita Líquida e dos indicadores financeiros Valor Presente Líquido e Razão Beneficio/Custo. O preço de venda dos grãos pode comprometer a viabilidade econômica e financeira da produção de milho safrinha em cenários pessimista de comercialização para o cultivo de sequeiro, assim como, preços pessimistas podem proporcionas receitas baixas quando em cultivo sob irrigação.

Palavras-chave: Zea mays L.; manejo de irrigação; déficit hídrico; retorno econômico; Preço de comercialização de grãos. 


\section{Introdução}

O milho (Zea mays L.) é uma cultura de grande importância econômica, por ser usado para alimentação humana, animal e também podendo ser utilizado para produção de biocombustíveis, desta forma desempenhando um importante papel para o desenvolvimento econômico e socioeconômico de muitos países devido a sua diversificação de utilização [1].

Esta cultura é cultivada em vários países, porém $65 \%$ da produção mundial está concentrada nos Estados Unidos, China e Brasil [2]. No Brasil o milho ocupa a segunda posição entre as culturas mais produzidas, atrás apenas da cultura da soja. Em 2019, a cultura do milho ocupou uma área cultivada superior a 17 milhões de hectares, com uma produção estimada de 99,984 milhões de toneladas de grãos [3].

A produtividade média brasileira de milho é de aproximadamente $5.000 \mathrm{~kg} \mathrm{ha}^{-1}$, estando atrás da produtividade média de países como a Argentina (7.442 kg ha-1), China (5.947 kg ha-1) e Estados Unidos (10.960 kg ha ${ }^{-1}$ ) [4]. A variabilidade pluviométrica é um dos principais fatores que limitam o crescimento da produtividade média em várias regiões produtoras no Brasil, uma vez que, para Gong et al. [5] a cultura é altamente exigente em termos de disponibilidade hídrica, e assim a quantidade e a distribuição pluviométrica são geralmente os principais fatores que influenciam na variabilidade produtiva em condições de sequeiro [6].

Neste contexto, a irrigação surge com uma técnica agrícola que propicia o aumento da produtividade e melhoria na qualidade dos produtos, incorporação de novas áreas ao sistema produtivo viabilizando a implantação de lavouras em regiões mais secas, nas quais sem a irrigação os plantios são impraticáveis ou de baixas produtividades, o que proporciona a redução dos riscos de perda da produção e a melhoria da qualidade de vida do homem do campo [7].

Outrossim, a utilização e o desenvolvimento de novas tecnologias que forneçam o uso eficiente e efetivo de irrigação são essenciais para manter a produção agrícola em níveis satisfatórios em relação à demanda mundial de alimentos [8]. Porém um dos grandes desafios nessa ótica é aumentar a produtividade e reduzir os custos para obter maiores rentabilidade e lucratividade, uma vez que, investir em um sistema de irrigação acrescentam despesas no sistema produtivo, devendo a produtividade adicional obtida proporcionar benefícios econômicos maiores que os custos relacionados ao sistema de irrigação [9].

Segundo Richetti [10], a análise dos custos de produção auxilia os agricultores a planejar investimentos, otimizar o capital investido e maximizar os lucros, sendo um dos fatores cruciais no planejamento do sistema produtivo/econômico. Do mesmo modo, outro fator econômico importante a ser considerado está a análise das receitas para distintos cenários de preço de grãos pagos ao produtor, que devido ao milho ser uma comodity produzida mundialmente vários fatores definem e interferem nos preços de comercialização, que sofrem grande variabilidade temporal e sazonal [11]. Em um levantamento realizado aos dados de comercialização de grãos de milho para 0 estado do RS no ano de 2018 a variação dos preços pagos aos produtores foi em torno de $\pm 17 \%$, da média anual.

Nesta acepção, a obtenção da produtividade de milho em sistemas de irrigação e, dos custos de produção fazem parte do processo de planejamento da irrigação. Ao mesmo tempo analisar as receitas obtidas com a produção, diante de diferentes cenários de preços de comercialização dos grãos auxiliam no suporte para a correta tomada de decisão ao produtor, sobre os investimentos no sistema produtivo. 
Diante do exposto, o objetivo deste trabalho foi determinar a produtividade do milho safrinha sob diferentes estratégias de irrigação suplementar, bem como analisar a viabilidade econômica e financeira da irrigação por aspersão convencional para diferentes cenários de comercialização de grãos.

\section{Material e Métodos}

Foram realizados dois experimentos de campo nas safras de 2011/2012 e 2012/2013 (experimento I e experimento II, respectivamente), na área experimental do Setor de Irrigação e Drenagem do Instituto Federal de Educação Ciência e Tecnologia Farroupilha, campus de Alegrete, RS, Brasil com coordenadas geográficas $29^{\circ} 42^{\prime}$ $52,85^{\prime \prime}$ de latitudes Sul, $55^{\circ} 31^{\prime} 29,69$ " de longitude Oeste e $121 \mathrm{~m}$ de altitude. O solo da área experimental é um Argissolo Vermelho Distrófico arênico [12], com granulometria $62,6 \% ; 12,1 \%$ e $25,2 \%$ de areia, silte e argila respectivamente. Clima subtropical úmido (Cfa) com temperaturas médias de 17,9 ${ }^{\circ} \mathrm{C}$ e média de precipitações de $1700 \mathrm{~mm}$, segundo a escala de Koopen [13].

Os experimentos foram conduzidos em um Delineamento Experimental de Blocos ao Acaso em 5 tratamentos e 3 repetições e foram semeados com auxilio de uma semeadora mecânica com espaçamento entre linhas de $0,45 \mathrm{~m}$, em seis de fevereiro de 2011 e seis de fevereiro de 2012, ambos sobre palhada de nabo forrageiro dessecado entre 15 e 25 dias antes da semeadura. O híbrido de milho utilizado foi 0 AS 1551 de ciclo precoce, com aproximadamente 9,5 sementes por metro quadrado.

No experimento I foram aplicadas as lâminas de irrigação de 50, 65, 75, 85 e 100\% da evapotranspiração da cultura (ETc) e no experimento II foram aplicadas as lâminas de irrigação de 0, 45, 72, 83 e 100\% da evapotranspiração da cultura (ETc). O manejo da irrigação foi realizado com base na evapotranspiração da cultura (ETc) obtida por meio da Equação 1:

$$
E T c=E T o . K c
$$

(Equação 1)

onde, ETo é a evapotranspiração de referência $(\mathrm{mm})$ obtida através de um tanque classe A, corrigidos com o fator $\mathrm{Kp}$, e o Kc é o Coeficiente de Cultura de acordo com Doorenbos \& Kassam [14]. Foi considerada para o manejo da irrigação a precipitação efetiva, sendo determinada de acordo com [15].

A irrigação foi exercida com um sistema do tipo aspersão convencional com espaçamento de $12 \times 12 \mathrm{~m}$. A diferenciação das lâminas de irrigação foi realizada pela sobreposição de água obtida através dos diferentes diâmetros de bocais dos aspersores. As irrigações foram executadas em um turno de rega prefixado de cinco dias, as doses aplicadas com base nas leituras diárias de evaporação do Tanque Classe A, (EV) e o volume de água aplicado, calculado através da multiplicação do acumulo de cinco dias de EV, multiplicado pelo coeficiente do tanque (Kp) e pelo coeficiente de cultura (Kc), obtidos de acordo com a metodologia de Büchele e Silva [16] e Doorenbos \& Kassam [14] respectivamente. Os dados meteorológicos para o cálculo do $\mathrm{Kp}$ assim como a precipitação foram coletados de uma estação meteorológica do Instituto Nacional de Meteorologia - INMET localizada $500 \mathrm{~m}$ da área experimental.

A colheita do milho foi realizada manualmente por unidade experimental, aos 145 DAE, quando os grãos apresentavam $20 \%$ de umidade. O material colhido foi 
submetido à secagem em estufa e posteriormente contabilizado os componentes de rendimento e umidade final para estimativa da produtividade através da Equação 2.

$$
\operatorname{Pgrãos}\left(t . h a^{-1}\right)=\frac{\text { densidadede plantas. } m^{-2} \times N E P \times N G E \times M C G(g)}{10000}
$$

(Equação 2)

Os dados obtidos foram avaliados estatisticamente por meio da análise de variância ANOVA. Os efeitos individuais dos submetido a análise de regressão considerando todos os testes estatísticos ao nível de $5 \%$ de probabilidade de erro. Para a análise estatística utilizou o software SISVAR 5.3 [17].

Para obtenção da receita bruta $(\mathrm{RB})$ realizou-se a multiplicação da produtividade de grãos $(\mathrm{Y})$, pelo preço do quilograma de milho em $\mathrm{R} \$ \mathrm{~kg}^{-1}(\mathrm{Pp})$. Para o preço do quilograma do produto considerou-se o valor médio de comercialização da região de estudo entre o período de 2013 e 2018 onde encontrou-se o valor médio de USD $0,177 \mathrm{~kg}$ (considerado como cenário médio - $\mathrm{CM}$ ). Além disso, considerou-se um cenário pessimista de comercialização de USD $0,128 \mathrm{~kg}(\mathrm{CP})$ e um Cenário Otimista de USD 0,226 kg (CO).

A receita líquida da produção $(R L)$ foi obtida pela diferença entre a $R B$ e os custos totais de produção Equação 3. Estes custos compreendem os custos não relacionados à irrigação (CNRI), os custos fixos relacionados a irrigação (CFRI) e os custos variáveis relacionados à irrigação (CVRI), sendo o CFRI e CVRI inexistente quando analisado o tratamento sem irrigação pois, nesta situação desconsiderou-se o uso do equipamento de irrigação.

$$
R L=\text { Yw. Pp }- \text { CNRI }- \text { CFRI }- \text { CVRI. W }
$$

onde, $R L$ é a receita liquida em $R \$$ ha $^{-1}$, CNRI é o custo não relacionado a irrigação em $R \$ h^{-1}$, CFRI é o custo fixo relacionado a irrigação em $R \$ h^{-1}$; CVRI é o custo variável relacionado com a irrigação em $R \$ \mathrm{~mm}^{-1}$ e W é a lâmina de irrigação em $\mathrm{mm}$. Os custos fixos não relacionados à irrigação (CFNRI) foram construídos de todas as operações e insumos necessários (número de horas-máquina, número de horas homens, preparo de solo, sementes, semeadura, colheita, herbicidas, pesticidas, terra, etc.), obtidos através da planilha eletrônica disponibilizada pela EPAGRI/CEPA [18] adaptado com insumos utilizados para cultivo de milho para média tecnologia (safrinha). Os custos relacionados à irrigação foram divididos em custos fixos (CFRI) e custos variáveis da irrigação (CVRI) e, para determiná-los, foi projetado um sistema de irrigação por aspersão convencional fixa, conforme metodologia proposta por Biscaro [19].

Para a projeção do sistema fixou-se os valores de: altura geométrica de sucção $5 \mathrm{~m}$; altura geométrica de recalque $15 \mathrm{~m}$; desnível da linha principal e das linhas laterais 2 $\mathrm{m}$; altura das elevações dos aspersores de $2 \mathrm{~m}$, comprimento da tubulação de recalque de $100 \mathrm{~m}$, comprimento da tubulação de sucção de $10 \mathrm{~m}$. Considerou-se como área total irrigada a distância entre os aspersores que se encontram na extremidade da área, mais duas vezes $60 \%$ do alcance dos aspersores, resultando em uma área de 1,3 ha, sendo este valor obtido no projeto corrigido para uma unidade de área (1 ha). Os preços dos componentes foram obtidos de peças e equipamentos comercializados na região, sendo as tubulações de PVC Azul (para irrigação), com os diâmetros comerciais encontrados e pressão nominal de serviço menor possível para 
cada setor (linhas laterais, principal, recalque e sucção). Para um mesmo setor foi selecionado apenas um diâmetro comercial.

Os CFRI foram calculados conforme Equação 4, proposta por CONAB [20],

$$
\mathrm{CFRI}=\mathrm{CD}+\mathrm{CJ}+\mathrm{CS}
$$

onde CD é a custo com a depreciação dos componentes do sistema em $R \$$ ha $^{-1}$, CJ é o custo com juro sobre o capital investido em $R \$$ ha $^{-1}$ e CS é o custo com seguro dos componentes do sistema de irrigação em $R \$ h^{-1}$. Foram considerados $50 \%$ deste custo devido ser em cultivo safrinha, ou seja, dividido com cultura anterior.

Os valores de CD foram calculados utilizando-se a Equação 5 [20],

$$
\mathrm{CD}=\frac{(\mathrm{VN}-\mathrm{VR})}{\mathrm{VUh}} \cdot \mathrm{HsTr}
$$

onde, VN é o valor de aquisição do componente novo em $R \$ h^{-1}$, VR é o valor residual do componente em $\mathrm{R} \$$ ha $^{-1}$, Vuh é a vida útil do componente em horas e HsTr é o total de horas trabalhadas pelo componente em horas. O valor residual ou de sucata foi calculado como $20 \%$ do valor de compra de cada componente do sistema. $E$ a vida útil utilizada foi de 20 anos.

Os valores de CJ foram calculados considerando-se a taxa de remuneração de 6,0\% ao ano, aplicados sobre o valor médio dos equipamentos, conforme a Equação 6 [20].

$$
\mathrm{CJ}=\{[((\mathrm{VN} . \mathrm{QM}) / 2) / \mathrm{CAT}] . \mathrm{HsTr}\} . \mathrm{J}
$$

onde, QM é a quantidade do bem, CAT é a capacidade de trabalho do bem (h) e J é a taxa de remuneração.

O valore de CS foi determinado como sendo $0,35 \%$ do valor médio do bem novo [20], conforme equação 7.

$$
\mathrm{CS}=(\mathrm{VN} / 2) \cdot 0,35 .(\mathrm{HsTr} / \mathrm{Vuh})
$$

Os valores de CVRI foram obtidos pelo custo de aplicação da lâmina de irrigação e o número de irrigações, da mão-de-obra empregada e da manutenção do sistema, conforme a Equação 8.

$$
\text { CVRI }=\mathrm{CvE}+\mathrm{CvMo}+\mathrm{CvMan}
$$

onde: CvE é o custo variável com energia elétrica em $R \$$, CvMo é o custo com mãode-obra empregada na irrigação em $R \$$ e CvMan é o custo com manutenção dos equipamentos em $R \$$.

O custo variável da energia elétrica foi calculado considerando a potência do conjunto motobomba e o tempo para aplicação da lâmina de irrigação Equação 9. 
onde, $\mathrm{Pw}$ é a potência do conjunto motobomba $\left(\mathrm{Kw} \mathrm{h}^{-1}\right)$, Ee é o preço da energia elétrica em $R \$ \mathrm{Kw}^{-1}$, T é o tempo para aplicação de um milímetro de água $\mathrm{h} \mathrm{mm}^{-1} \mathrm{e} \mathrm{w}$ é a lâmina de irrigação $\mathrm{mm} \mathrm{ha}^{-1}$.

A determinação da potência necessária para aplicação de um milímetro de água via irrigação foi calculada com os dados do projeto para um hectare.

O valor da energia considerado foi de USD $0,102 \mathrm{~kW} \mathrm{~h}^{-1}$, considerando o preço na tarifa verde estabelecidos pela Agencia Nacional de Energia Elétrica - ANEEL.

O custo de mão de obra foi calculado utilizando o tempo proposto de 0,5 horas por hectare em cada setor do sistema e por irrigação [21], considerando o valor da hora trabalhada equivalente ao salário mínimo rural, conforme CONAB [20], como na Equação 10.

$$
\text { CvMo }=\text { Ni. Ns. 0,5. VSMin/220. } \mathrm{w} / 100
$$

onde, Ni é o número de irrigações, Ns é o número de setores do sistema de irrigação e VSMin é o valor do salário mínimo rural em $\mathrm{R} \$$.

O número de setores do sistema de irrigação foi de seis, determinado na confecção do projeto. O valor do salário mínimo rural utilizado foi de USD 377,88.

Os valores dos custos com manutenção foram calculados sobre $1 \%$ do valor do bem novo do sistema de irrigação, acrescido de $10 \%$ do valor gasto com energia [20], conforme a Equação 11.

$$
\mathrm{CvMan}=\text { VN. 0,01. }(\mathrm{CvE} / 10)
$$

Como indicadores de viabilidade financeira considerou-se o Valor Presente Líquido (VPL) e a Relação Benefício Custo (RBC). O VPL é definido como a diferença entre o valor presente dos benefícios e o valor presente dos custos, conforme Equação 12.

$$
\mathrm{VPL}=\sum_{\mathrm{t}=0}^{\mathrm{N}} \frac{\mathrm{Ft}}{(1+\mathrm{j})^{\mathrm{t}}}
$$

onde, VPL - valor presente líquido, em $R \$ h^{-1} ; j$ - taxas de desconto ou taxa mínima de atratividade (TMA), em decimal; $\mathrm{N}$ - horizonte do projeto, em anos; $\mathrm{t}$ - período do projeto, em anos e $\mathrm{Ft}$ - fluxo de caixa líquido em cada ano, em $\mathrm{R} \$ \mathrm{ha}^{-1}$.

A razão benefício/custo foi calculada por meio da Equação 13.

$$
\mathrm{RBC}=\frac{\sum_{\mathrm{t}=0}^{\mathrm{n}} \mathrm{B} /(1+\mathrm{j})^{\mathrm{t}}}{\sum_{\mathrm{t}=0}^{\mathrm{n}} \mathrm{C} /(1+\mathrm{j})^{\mathrm{t}}}
$$

onde, $\mathrm{RBC}$ - razão benefício/custo; $B$ - receitas, em $\mathrm{R} \$$ ha ${ }^{-1}$ e $C$ - despesas, em $\mathrm{R} \$$ ha 1 . 
Adotou-se uma TMA de 6\% ao ano, e um horizonte de projetos de 20 anos, conforme vida útil do sistema de irrigação.

Após a análise para os diferentes cenários considerou-se viável o manejo que apresentou VPL positivo e RBC maior que 01.

\section{Resultados e Discussões}

\subsection{Precipitações e irrigação}

O volume das precipitações pluviais efetivas entre os dois experimentos assim como o volume de água via irrigação foi divergente. No experimento I a precipitação acumulada foi de $207 \mathrm{~mm}$ enquanto que no experimento II foi de $501 \mathrm{~mm}$. Em relação suplementação de água no experimento 1 houve a necessidade de 18 irrigações equivalendo a $450 \mathrm{~mm}$ de suplementação hídrica no tratamento de reposição de $100 \%$ da ETc. Já no experimento 2 foram necessárias 9 irrigações e $111 \mathrm{~mm}$ de suplementação hídrica para a reposição de $100 \%$ da ETc.

Os volumes de precipitação e irrigação para cada tratamento de irrigação e ano de estudo podem ser observados na Tabela 1.

Tabela 2. Precipitação e irrigação para o milho safrinha nas diferentes lâminas de irrigação no ano de 2011/2012 e 2012/2013.

\begin{tabular}{|c|c|c|c|c|}
\hline \multicolumn{5}{|c|}{ Experimento I (2012) } \\
\hline $\begin{array}{c}\text { Lâmina de Irrigação } \\
\text { (\% ETc) }\end{array}$ & $\begin{array}{l}\text { Precipitação } \\
\text { Efetiva (mm) }\end{array}$ & $\begin{array}{l}\text { Número de } \\
\text { irrigações }\end{array}$ & $\begin{array}{l}\text { Irrigação Total } \\
(\mathbf{m m})\end{array}$ & $\begin{array}{l}\text { Lâmina Total } \\
(\mathrm{mm})\end{array}$ \\
\hline 50 & & 18 & 121 & 329 \\
\hline 65 & & 18 & 157 & 365 \\
\hline 75 & 207 & 18 & 182 & 389 \\
\hline 85 & & 18 & 206 & 413 \\
\hline 100 & & 18 & 242 & 450 \\
\hline \multicolumn{5}{|c|}{ Experimento II (2013) } \\
\hline $\begin{array}{c}\text { Lâmina de Irrigação } \\
\text { (\% ETc) }\end{array}$ & $\begin{array}{l}\text { Precipitação } \\
\text { Efetiva (mm) }\end{array}$ & $\begin{array}{l}\text { Número de } \\
\text { irrigações }\end{array}$ & $\begin{array}{l}\text { Irrigação Total } \\
(\mathrm{mm})\end{array}$ & $\begin{array}{l}\text { Lâmina Total } \\
(\mathbf{m m})\end{array}$ \\
\hline 0 - Sem irrigação & & 0 & 0,0 & 787 \\
\hline 45 & & 9 & 50 & 837 \\
\hline 72 & 501 & 9 & 80 & 867 \\
\hline 83 & & 9 & 92 & 879 \\
\hline 100 & & 9 & 111 & 898 \\
\hline
\end{tabular}

A demanda hídrica necessária para a obtenção de boas produtividades na cultura do milho é de 400 a $600 \mathrm{~mm}$ [22], portanto, a precipitações efetiva ocorrida no experimento 01 não foi suficiente para o correto desenvolvimento da cultura com o volume efetivo de $207 \mathrm{~mm}$ de chuva, e déficit de $272 \mathrm{~mm}$. Para o experimento 2, embora os $501 \mathrm{~mm}$ ocorridos estarem dentro dos parâmetros sugeridos por Bergamaschi e Matzenauer [22] a distribuição das chuvas foi irregular, sendo necessário a reposição de $111 \mathrm{~mm}$ de água, através da irrigação.

Para Nied et al. [23] a distribuição da precipitação durante o período de cultivo de milho no Rio Grande do Sul tem ocorrido de maneira muito irregular ao longo dos últimos anos, com períodos de elevados volumes e outros de escassez hídrica, o que 
caracteriza insegurança na produção de milho, igualmente ao cultivado na safrinha. Neste período as precipitações em determinados momentos são insuficientes ou são mal distribuídas ao longo do tempo para atender as necessidades das culturas, afetando significativamente a produtividade, principalmente em cultivos de sequeiro.

\subsection{Produtividade de grãos}

Com a ocorrência do déficit hídrico os resultados demonstram que a irrigação suplementar proporcionou efeito positivo sobre a produtividade de grãos do milho para os dois anos de experimento avaliados, como pode ser observado na Figura 1.

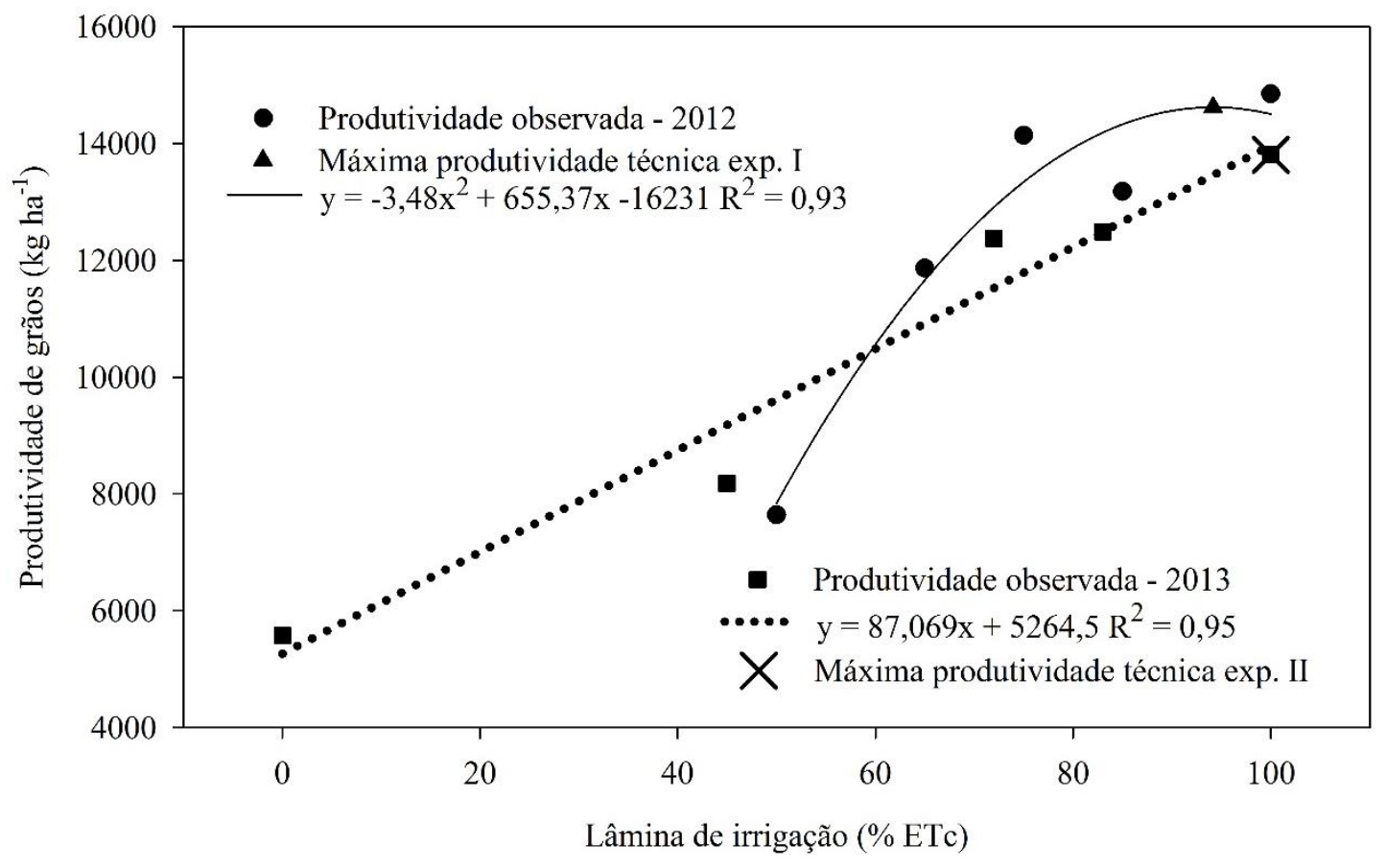

Figura 1. Produtividade de grãos de milho safrinha para as diferentes lâminas de irrigação para os anos de 2011/2012 e 2012/2013, em Alegrete, RS.

No experimento I, embora todos os tratamentos testados tenham recebido irrigação suplementar, a produtividade de grãos apresentou um aumento quadrático em relação a lâmina de água aplicada, atingindo uma produtividade no ponto de máxima eficiência técnica, estimada em 14624,6 $\mathrm{kg} \mathrm{ha}^{-1}$, com a reposição de água de $94 \%$ da ETc. Já a produtividade mais baixa foi de $7642,6 \mathrm{~kg} \mathrm{ha}^{-1}$ verificada na menor lâmina testada (50\% da ETc). Para o experimento II a produtividade de grão apresentou-se linear à lâmina de irrigação testada. Consequentemente a maior produtividade observada foi de $13809,4 \mathrm{~kg} \mathrm{ha}^{-1}$, na lâmina de $100 \%$ da ETc e a menor de $5576,1 \mathrm{~kg} \mathrm{ha}^{-1}$, no tratamento sem irrigação.

Resultados que corroboram com esta pesquisa foram observados por Martins et al. [24], onde as produtividades do milho também aumentaram de acordo com a elevação do volume de água para cada lâmina de irrigação. Para Mendoza-Pérez et al. [25] a falta de água nos estágios fenológicos de floração e enchimento de grãos reflete negativamente na produtividade.

A amplitude de variação de produtividade entre os anos agrícolas avaliados e a diferença na obtenção da função de produção quadrática (experimento 1) e linear 
(experimento 2) é conferida a irregularidade na distribuição das chuvas e das condições climáticas ocorridas. Assim também como a deficiência hídrica, a radiação solar e a temperatura também foram distintas entre os anos, sabe-se que em anos menos chuvosos os valores de radiação são superiores que em anos mais chuvosos, devido ocorrerem períodos mais nublados.

Além disso, estes fatores são responsáveis diretos pela evapotranspiração da cultura o que por consequência influenciaram a produtividade do milho. No experimento 10 déficit hídrico foi maior que o experimento 2, com isso, as plantas que receberam as maiores lâminas de água por irrigação responderam superiormente, em comparação ao experimento 2 .

\subsection{Componentes do custo}

A composição dos custos de produção, e dos relacionados a irrigação para cada tratamento estão representados na Tabela 2.

Tabela 3. Componentes dos custos não relacionados com a irrigação (CFNRI), custos fixos relacionados com a irrigação (CFRI) e custos variáveis relacionados com a irrigação (CVRI) para o cultivo do milho safrinha safras 2011/2012 e 2012/2013.

\begin{tabular}{|c|c|c|c|c|}
\hline \multicolumn{5}{|c|}{ Custos e produção (US\$ ha-1) } \\
\hline Variável analisada & \multicolumn{2}{|c|}{ Experimento I } & \multicolumn{2}{|c|}{ Experimento II } \\
\hline CFNRI & \multicolumn{2}{|c|}{720,00} & \multicolumn{2}{|c|}{720,00} \\
\hline \multicolumn{5}{|c|}{ Custos Fixos da Irrigação (CFI) } \\
\hline CD & \multicolumn{2}{|c|}{36,47} & \multicolumn{2}{|l|}{36,47} \\
\hline CJ & \multicolumn{2}{|l|}{27,35} & \multicolumn{2}{|l|}{27,35} \\
\hline $\mathrm{CSe}$ & \multicolumn{2}{|l|}{07,98} & \multicolumn{2}{|l|}{07,98} \\
\hline \multirow[t]{3}{*}{ CFRI } & \multicolumn{2}{|l|}{71,80} & \multicolumn{2}{|l|}{71,80} \\
\hline & \multicolumn{4}{|c|}{ ustos Variáveis da Irrigação (CVI) } \\
\hline & $\begin{array}{l}\text { Lâmina de } \\
\text { irrigação (\% } \\
\text { Etc) }\end{array}$ & Custo & $\begin{array}{l}\text { Lâmina de } \\
\text { irrigação (\% } \\
\text { Etc) }\end{array}$ & Custo \\
\hline \multirow{5}{*}{ CVe } & 50 & 28,33 & - & - \\
\hline & 65 & 36,76 & 45 & 11,64 \\
\hline & 75 & 42,62 & 72 & 18,63 \\
\hline & 85 & 48,24 & 83 & 21,48 \\
\hline & 100 & 56,67 & 100 & 25,87 \\
\hline \multirow{5}{*}{ CVMO } & 50 & 112,22 & - & - \\
\hline & 65 & 145,61 & 45 & 46,12 \\
\hline & 75 & 168,80 & 72 & 73,79 \\
\hline & 85 & 191,06 & 83 & 85,06 \\
\hline & 100 & 224,45 & 100 & 102,49 \\
\hline \multirow{5}{*}{ CVMan } & 50 & 21,12 & - & - \\
\hline & 65 & 21,96 & 45 & 19,45 \\
\hline & 75 & 22,55 & 72 & 20,15 \\
\hline & 85 & 23,11 & 83 & 20,43 \\
\hline & 100 & 23,95 & 100 & 20,87 \\
\hline \multirow{5}{*}{ CVRI } & 50 & 161,68 & - & - \\
\hline & 65 & 204,34 & 45 & 77,21 \\
\hline & 75 & 233,96 & 72 & 112,57 \\
\hline & 85 & 262,41 & 83 & 126,97 \\
\hline & 100 & 305,07 & 100 & 149,23 \\
\hline
\end{tabular}


Observa-se que o CFRI obtido foi de igual valor para ambos os anos, sendo de USD 71,80 ha. Este custo abrange à depreciação do sistema de irrigação, os juros sobre o capital investido e o seguro do equipamento de irrigação, considerando um horizonte de projeto de 20 anos de vida útil. Salienta-se que devido ao cultivo ser realizado na safrinha, considerou-se que o CFRI seria rateado entre a cultura antecessora da safra, considerando para este trabalho $50 \%$ do valor total anual deste custo.

Já o custo com a implantação da lavoura, independente da irrigação, ou seja, o CFNRI foi de USD 720,00 ha para ambos os anos avaliados. Já o CVRI apresentou variação conforme o número de irrigações e o volume de água aplicado nas diferentes lâminas de irrigação. Observa-se ainda que entre os experimentos, o menor CVRI foi encontrado na safra agrícola de 2012/2013 (Experimento II) no valor de USD 149,23 por hectare, o que é justificado pelo menor volume de água aplicado de $111 \mathrm{~mm} \mathrm{em}$ relação aos $242 \mathrm{~mm}$ em 2011/2012 (Experimento I), comparando a lâmina de 100\% da ETc, onde o custo foi de USD 305,07 por hectare.

Observa-se também que a introdução do sistema de irrigação por aspersão convencional aumentou o custo total do sistema produtivo em $39,5 \%$ e $52,3 \%$ para o experimento I e II respectivamente, considerando como parâmetro uma unidade de área (um hectare) e o tratamento de reposição de $100 \%$ da ETc, comparado a inexistência de um sistema de irrigação.

A discrepância ocorrida entre os custos relacionados a irrigação entre os experimentos deve-se ao custo variável da irrigação, pois no experimento I foram necessários a aplicação de 242 mm (lâmina 100 \% ETc), o que proporcionou maiores despesas com energia elétrica, mão de obra e manutenção, em comparação ao experimento II, onde foram necessários $111 \mathrm{~mm}$ de suplementação de água na lâmina de 100\% da ETc.

Para efeito de comparação, autores como Oliveira e Zocoler [26], encontraram um acréscimo médio de $18,15 \%$ de participação do custo da irrigação no custo total da produção, um valor mais abaixo dos observados neste trabalho, porém salienta-se que para estes autores o sistema de irrigação adotado era por pivô central, e foram considerados outros valores de custo com energia elétrica.

\subsection{Custo total e receitas}

$\mathrm{Na}$ Tabela 3, apresenta-se a receita bruta, o custo total e a receita líquida, para os 3 cenários de comercialização de grãos. Em ambos experimentos a maior taxa de crescimento da receita líquida entre os tratamentos foram proporcionados pela lâmina de $100 \%$ da ETc.

Para o experimento I, em um cenário de venda de grãos pessimista a maior receita líquida foi de USD 759,90 ha na lâmina de $100 \%$, enquanto que a menor foi na lâmina de $50 \%$, com valor de USD 49,72 ha de receita líquida. Ao mesmo tempo analisando os cenários Médio e Otimista, a receita líquida para a lâmina de $100 \%$ apresentou valores de USD 1470,69 ha e USD 2181,49 ha, enquanto que USD 433,76 e USD 817,80 ha, para a lâmina de $50 \%$, respectivamente.

Do mesmo modo, para o experimento II, o valor de receita líquida para um cenário de venda pessimista foi de USD 847,30 ha para a lâmina de reposição de $100 \%$ da ETc. Entretanto, na lâmina de $0 \%$ da ETc a receita bruta obtida foi menor que os custos totais, ocasionando em prejuízo na produção de milho, ou seja, sendo economicamente inviável o cultivo de milho safrinha sem 0 uso de irrigação, considerando um valor de venda de USD $0,128 \mathrm{~kg}$. 
Tabela 4 - Receita Bruta - RB, Custo Total - CT e Receita Líquida - RL para cenários de venda de grãos de Pessimista - CP (US\$ 0,128 kg), Médio - CM (US\$ 0,177 kg) e Otimista - CO (US\$ 0,226 kg), para as diferentes lâminas de irrigação e safras $2011 / 2012$ e 2012/2013.

\begin{tabular}{|c|c|c|c|c|c|c|c|}
\hline \multirow{2}{*}{ \% ETc } & \multicolumn{3}{|c|}{ RB (US\$ ha-1) } & \multirow{2}{*}{$\begin{array}{c}\text { CT } \\
\left(\mathrm{US} \$ \mathrm{ha}^{-1}\right)\end{array}$} & \multicolumn{3}{|c|}{ RL (US\$ ha $\left.{ }^{-1}\right)$} \\
\hline & CP & CM & CO & & CP & CM & $\mathrm{CO}$ \\
\hline 50 & 1003,20 & 1387,24 & 1771,28 & 953,48 & 49,72 & 433,76 & 817,80 \\
\hline 65 & 1493,13 & 2064,71 & 2636,30 & 996,14 & 496,99 & 1068,57 & 1640,16 \\
\hline 75 & 1708,38 & 2362,37 & 3016,37 & $1.025,77$ & 682,62 & 1336,61 & 1990,60 \\
\hline 85 & 1834,55 & 2536,84 & 3239,13 & $1.054,21$ & 780,35 & 1482,64 & 2184,93 \\
\hline 100 & 1856,77 & 2567,56 & 3278,36 & $1.096,87$ & 759,90 & 1470,69 & 2181,49 \\
\hline 0 & 673,86 & 931,82 & 1189,78 & 720,00 & $-46,14$ & 211,82 & 469,78 \\
\hline 45 & 1175,37 & 1625,32 & 2075,27 & 869,01 & 306,36 & 756,31 & 1206,26 \\
\hline 72 & 1476,28 & 2041,42 & 2606,56 & 904,37 & 571,92 & 1137,06 & 1702,20 \\
\hline 83 & 1598,88 & 2210,95 & 2823,02 & 918,77 & 680,10 & 1292,17 & 1904,24 \\
\hline 100 & 1788,34 & 2472,94 & 3157,54 & 941,03 & 847,30 & 1531,90 & 2216,50 \\
\hline
\end{tabular}

Já quando considerado para o tratamento $0 \%$ da ETc, os cenários médio e otimista evidencia-se valores positivos de receita líquida, muito embora apresentem valores $623,2 \%(\mathrm{CM})$ e $371,8 \%(\mathrm{CO})$, menores em relação ao cultivo irrigado na lâmina de $100 \%$ da ETc.

Portando nota-se a importância da irrigação suplementar no milho safrinha, onde mesmo com valores de venda baixo, propicia produtividades que viabilizam receitas superiores aos custos mesmo em cenários de venda adversos.

Muito embora a irrigação seja viável em cenários pessimistas de venda de grãos, como podemos observar na tabela 3 , o preço pago ao produtor é um dos principais aspectos que definem o sucesso na produção de milho safrinha, uma vez que, preços baixos podem ocasionar prejuízos em cultivos de sequeiro, ou receitas baixas mesmo quando em cultivo sob irrigação.

Os resultados da receita líquida desta pesquisa estão de acordo com o trabalho de Martins et al. [24], onde estudando duas safras agrícolas sobre milho irrigado por gotejamento, constataram que ambas ocasiões as lâminas maiores proporcionaram maiores valores de receita líquida. Em um estudo desenvolvido por Pegorare et al. [27] também observaram um aumento nos incrementos produtivos com as maiores lâminas, porém devido aos altos custos com energia elétrica (característica do local de estudo), as maiores lâminas não apresentaram a maior receita líquida.

\subsection{Indicadores financeiros}

Analisou-se os indicadores financeiros Valor Presente Líquido (VPL), Taxa Interna de Retorno (TIR) e Razão Beneficio Custo (RBC), para um horizonte de 20 anos e uma taxa de atratividade de $6 \%$ ao ano, para os diferentes cenários de venda de grãos e tratamentos de irrigação. Os resultados obtidos encontram-se na Tabela 4.

Em relação ao VPL observou-se retornos positivos para a maioria das lâminas testadas e cenários de venda de produto utilizados, excetuando somente para 0 cenário pessimista, onde para as lâminas de 50\% (experimento I) e $0 \%$ (experimento II) da ETc, os valores foram negativos de USD $-1624,02$ ha para o experimento I e USD -2723,60 ha para o experimento II, representando que o investimento é inviável nestas condições. 
Tabela 5. Indicadores financeiros Valor Presente Líquido, Taxa Interna de Retorno e Razão Beneficio/Custo para os diferentes cenários de venda de grãos e lâminas de irrigação.

\begin{tabular}{|c|c|c|c|c|c|c|c|c|c|}
\hline \multicolumn{10}{|c|}{ Experimento I (2011/2012) } \\
\hline$(\%$ & \multicolumn{3}{|c|}{ VPL } & \multicolumn{3}{|c|}{ TIR } & \multicolumn{3}{|c|}{$\mathbf{R B} / \mathbf{C}$} \\
\hline Etc) & $\mathbf{C P}$ & $\mathbf{C M}$ & $\mathrm{CO}$ & CP & CM & $\mathrm{CO}$ & CP & CM & CO \\
\hline 50 & $-1624,02$ & 2780,86 & 7185,74 & $-3 \%$ & $18 \%$ & $35 \%$ & 0,9 & 1,2 & 1,5 \\
\hline 65 & & 10062,13 & 166 & $21 \%$ & $46 \%$ & $70 \%$ & 1,3 & 1,7 & 2,2 \\
\hline 75 & & 13136,47 & 20 & $29 \%$ & $57 \%$ & $85^{\circ}$ & 1,4 & 1,9 & 2,5 \\
\hline 85 & & 14811,39 & $22 \varepsilon$ & $33 \%$ & $63 \%$ & 93 & 1,5 & 2,0 & 2,6 \\
\hline 100 & & 14674,40 & 22827,15 & $32 \%$ & $63 \%$ & & 1,4 & 2,0 & 2,5 \\
\hline \multicolumn{10}{|c|}{ Experimento II (2012/2013) } \\
\hline$(\%$ & \multicolumn{3}{|c|}{ VPL } & \multicolumn{3}{|c|}{ TIR } & \multicolumn{3}{|c|}{ RB/C } \\
\hline Etc) & $\mathbf{C P}$ & CM & & $\mathbf{C P}$ & $\mathrm{CM}$ & $\mathrm{CO}$ & $\mathbf{C P}$ & CM & $\mathrm{CO}$ \\
\hline 0 & $-2723,60$ & 235,19 & & $-13 \%$ & $7 \%$ & $20 \%$ & 0,7 & 1,0 & 1,3 \\
\hline 45 & 1319,61 & 6480,47 & 11641,33 & $12 \%$ & $32 \%$ & $52 \%$ & 1,1 & 1,5 & 1,9 \\
\hline 72 & 4365,49 & 10847,60 & 17329,71 & $24 \%$ & $49 \%$ & $73 \%$ & 1,3 & 1,9 & 2,4 \\
\hline 83 & 5606,41 & 12626,80 & 19647,20 & $29 \%$ & $55 \%$ & $81 \%$ & 1,4 & 2,0 & 2,5 \\
\hline 100 & 7524,19 & 15376,48 & 23228,77 & $36 \%$ & $65 \%$ & $95 \%$ & 1,6 & 2,2 & 2,8 \\
\hline
\end{tabular}

Já os maiores ganhos financeiros podem ser alcançados com as lâminas de $85 \%$ e $100 \%$ da ETc, onde os benefícios serão de USD 6756,18, USD 14811,39 e USD 22866,60 ha, para CP, CM e CO, respectivamente, no experimento I e USD 7524,19 USD 15376,48 e USD 23228,77 ha, para CP, CM e CO, respectivamente no experimento II.

Os mesmos resultados apontados para o VPL podem ser considerados para a RBC e a TIR. Portanto é inviável a realização do investimento para o uso de lâminas de reposição de $50 \%$ da ETc, no experimento I, pois, em um cenário pessimista de venda, para cada dólar investido retornam apenas 0,9 e a TIR obtida é menor que a TMA (6\%)..

Já no experimento II o investimento é inviável no cultivo de sequeiro e cenário pessimista onde para cada dólar aplicado retornam somente 0,7. Logo, os maiores retornos são observados na lâmina $85 \%$ da Etc onde para cada dólar investido retornam 2,6 no experimento I, e na lâmina de $100 \%$ da ETc no experimento II que para cada dólar retornam 2,8, considerando o cenário otimista.

A disparidade do VPL, da TIR e da RBC encontrados em comparação aos anos agrícolas estudados deve-se a diferença na intensidade do déficit hídrico ocorrido em cada safra, o que afetou de modo distinto a produtividade obtida em cada experimento. No experimento I, o déficit hídrico foi mais intenso, afetando mais consideravelmente a produtividade dos tratamentos que receberam as menores lâminas de água via irrigação, diferentemente do experimento II, onde o déficit hídrico foi menor e influenciou menos a produtividade de grãos e por consequência os retornos financeiros.

Em um estudo semelhante a este realizado por Osti et al. [28] onde avaliou as lâminas de 140, 190 mm, 290 e 388 mm, os autores destacam que a RBC para as lâminas de 190 e 290 proporcionaram maior retorno financeiro e rentabilidade de 5\% proporcionalmente. Neste caso, apesar de a maior lâmina de irrigação testada (388 
$\mathrm{mm}$ ) ter proporcionado maior produtividade, não foi suficiente para gerar receitas que pudessem cobrir os custos; com isso, sua rentabilidade foi muito baixa.

Já Xue et al. [29], com a imposição de restrições no volume de água disponível para irrigação e o aumento nos custos de água e de energia, constatou que a irrigação do milho nas Planícies Altas do Texas - EUA, com reposição de 75 a $80 \%$ da ETc é o manejo economicamente mais viável.

\section{Conclusão}

A cultura do milho conduzido na safrinha apresenta resposta de incremento de produtividade de grãos quando submetido a irrigação suplementar.

A introdução do sistema de irrigação por aspersão convencional aumenta os custos de produção de milho safrinha entre $39,5 \%$ e 52,3\% em relação ao cultivo de sequeiro.

Lâminas de irrigação entre $85 \%$ e $100 \%$ da ETc proporcionam as maiores valores de Receita Líquida e dos indicadores financeiros Valor Presente Líquido, Taxa Interna de Retorno e Razão Beneficio/Custo.

Os indicadores Valor Presente Líquido e Razão Beneficio/Custo demonstram que a irrigação é viável financeiramente, com retorno mais significativos quanto maior o cenário de venda dos grãos.

O preço de venda dos grãos pode comprometer a viabilidade econômica e financeira da produção de milho safrinha em cenários pessimista de comercialização para 0 cultivo de sequeiro, assim como, preços pessimistas podem proporcionas receitas baixas quando em cultivo sob irrigação.

\section{Referências}

[1] Greaves G. E., Wang Y. M. Effect of regulated deficit irrigation scheduling on water use of corn in southern Taiwan tropical environment. Agricultural Water Management 2017; 188:115-125. https://doi.org/10.1016/j.agwat.2017.04.008.

[2] USDA - Departamento de Agricultura dos Estados Unidos. Safra Mundial de Milho 2016/17 - 11ํㅡㄴ Levantamento do USDA. Informativo.

[3] CONAB - Companhia Nacional de Abastecimento. Acompanhamento da safra brasileira de grãos 2019; 7(3):69-77. Disponível em: <https://www.conab.gov.br/component/k2/item/download/28519_1451c80af85a090130 32c62c38317623>. Acesso em: 19 fev. 2021.

[4] FAOSTAT- Food Agriculture Organization of The United Nations. Comparação de dados. Produção. 2017. Disponível em: <www.fao.org/faostat/en/\#da-ta> Acesso em: 19 fev. 2021.

[5] Gong F., Wu X., Zhang H., Chen Y., Wang W. Making better maize plants for sustainable grain production in a changing climate. Frontiers in plant science 2015; 6:835. https://doi.org/10.3389/fpls.2015.00835.

[6] Araus J. L., Serret M. D., Edmeades G.O. Phenotyping maize for adaptation to drought. Frontiers in Physiology 2012; 3:305. https://doi.org/10.3389/fphys.2012.00305. 
[7] Soares F. C., Parizi A. R. C., Silva G. U., Essi R., Russi J. L., Ben L. H., Santos P.R. Irrigação suplementar na produção de grãos e na eficiência de uso da água do feijoeiro. Revista Agrarian 2016; 9(34):374-382. Disponível em: <https://ojs.ufgd.edu.br/index.php/agrarian/article/view/4235>. Acesso em: $19 \mathrm{fev}$. 2021.

[8] Oliveira Z. B. de. Rendimento de grãos de milho irrigado por gotejamento subterrâneo e estimativa da irrigação com dados da previsão do tempo. Revista Brasileira de Engenharia de Biossistemas 2018; 12(1):40-51. http://dx.doi.org/10.18011/bioeng2018v12n1p40-51.

[9] Pereira R. M., Júnior J. A. Casaroli D., Sales D. L., Rodriguez W. D. M., Souza J. M. F. Viabilidade econômica da irrigação de cana-de-açúcar no cerrado brasileiro. Irriga 2015; 1(2):149-157. ttp://dx.doi.org/10.15809/irriga.2015v1n2p149.

[10] RICHETTI, A. Viabilidade econômica da cultura da soja na safra 2014/2015, em Mato Grosso do Sul. Dourados: EMBRAPA, 2014. (Comunicado técnico, 194). Disponível em: <https://ainfo.cnptia.embrapa.br/ digital/bitstream/item/105124/1/COT2013194.pdf >. Acesso em: 6 dez. 2020.

[11] Tibulo C., Tibulo V. D. C. Previsão do preço do milho, através de séries temporais. Scientia Plena 2014;10(10). Disponível em: <https://www.scientiaplena.org.br/sp/article/view/1904>. Acesso em: 19 fev. 2021.

[12] Streck E. V., Kampf N., Dalmolin R. S. D., Klamt E., Nascimento P. C. do, Schneider E., Pinto L. F. S. Solos do Rio Grande do Sul. 2. ed. Porto Alegre, RS: EMATER, 2008. 222 p.

[13] Moreno J. A. Clima do Rio Grande do Sul. Porto Alegre: Secretária da Agricultura, 1961. 42p.

[14] Doorenbos J., Kassam A. H. Efectos del água sobre el rendimiento de los cultivos. Roma: FAO, 1979. 212 p. (Estudio FAO: Riego y Drenaje, 33).

[15] Millar A. A. Drenagem de terras agrícolas. Petrolina: Sudene, 1974. 164 p.

[16] Büchele F. A., Silva J. A. da. Manual prático de irrigação por aspersão em sistemas convencionais. Florianópolis: EPAGRI, 1992. 81p. (EPAGRI. Boletim Técnico, 58).

[17] Ferreira D. F. Sisvar - sistema de análise de variância para dados balanceados. Lavras, MG: UFLA, 1998. 19 p.

[18] EPAGRI/CEPA - Centro de Socioeconomia e Planejamento Agrícola, Custo de Produção safra milho alta tecnologia safra 2016/17, 2017. Disponível em: $<$ http://docweb.epagri.sc.gov.br/website_epagri/Sintese-Anual-da-Agricultura-

SC_2016_17.pdf>. Acesso em: 19 fev. 2021.

[19] Biscaro G. A. Sistemas de irrigação por aspersão. Dourados. Editora da UFGD, 2009.1 134p. Disponível em: <https://omp.ufgd.edu.br/omp/index.php/livrosabertos/catalog/book/49>. Acesso em: 19 fev. 2021.

[20] CONAB - Companhia Nacional de Abastecimento. Custos de produção agrícola: a metodologia da CONAB. Brasília: CONAB, 2010. 60 p. Disponível em: 
<https://www.passeidireto.com/arquivo/67864823/custos-de-producao-agricola-ametodologia-da-conab>. Acesso em: 19 fev. 2021.

[21] Marouelli W. A., Silva W. L. C. Seleção de sistemas de irrigação para hortaliças. 2.ed. Brasília: Embrapa Hortaliças, 2011. 20 p. Circular Técnica, 11. Disponível em: <https://ainfo.cnptia.embrapa.br/digital/bitstream/item/75698/1/ct-98.pdf>. Acesso em: 19 fev. 2021.

[22] Bergamaschi H., Matzenauer R. O milho e o clima. 1. ed. Porto Alegre, RS: Emater-Ascar, 2014. 84 p.

[23] Nied A. H., Heldwein A. B., Estefanel V., Silva J. C., Alberto C. M. Épocas de semeadura do milho com menor risco de ocorrência de deficiência hídrica no município de Santa Maria, RS Brasil. Ciência Rural 2005; 35(5):995-1002. https://doi.org/10.1590/S0103-84782005000500003.

[24] Martins J. D., Petry M. T., Rodrigues G. C., Carlesso R. Viabilidade econômica da irrigação deficitária em milho irrigado por gotejamento. Irriga 2016; 1(1):150-165. http://dx.doi.org/10.15809/irriga.2016v1n1p150-165.

[25] Mendoza-Pérez C., Sifuentes-Ibarra E., Ojeda-Bustamante W., Macías-Cervantes J. Response of surface-irrigated corn to regulated deficit irrigation. Ingeniería Agrícola y Biosistemas, Chapingo 3(1):29-40. https://doi.org/10.5154/r.inagbi.2016.03.001.

[26] Oliveira J. S., Zocoler J. L. Custos da irrigação e receita líquida dofeijoeiro em um sistema pivô central sob variação do comprimento da tubulação derecalque e desnível topográfico. Engenharia Agrícola 2013; $33(1), \quad 121-128$. http://dx.doi.org/10.1590/S0100-69162013000100013.

[27] Pegorare A. B, Fedatto E, Pereira S., Souza L. C. F, Fietz C. R. Irrigação suplementar no ciclo do milho "safrinha" sob plantio direto. Revista Brasileira de Engenharia Agrícola e Ambiental 2009; 13(3):262-271. https://doi.org/10.1590/S141543662009000300007.

[28] Osti A. M., Dallacort R., Tieppo R. C., Grzebieluckas C. E., Conceição A. M. Rentabilidade do milho e do feijão submetido a diferentes lâminas de irrigação em Mato Grosso. Revista de Economia e Sociologia Rural 2019; 57(4):505-518. https://doi.org/10.1590/1806-9479.2019.186329.

[29] Xue Q., Marek T. H., Xu W., Bell J. Irrigated corn production and management in the Texas High Plains. Journal of Contemporary Water Research and Education, Carbondale 2017; 162(1):31-41.

\section{Autores}

Luis Humberto Bahú Ben ${ }^{1 *}$, Ana Rita Costenaro Parizi ${ }^{2}$, Fátima Cibele Soares ${ }^{3}$, Anderson Crestani Pereira ${ }^{4}$, Ricardo Benetti Rosso ${ }^{5}$, Leonita Beatriz Girardi ${ }^{6}$, Marcos Vinicius Loregian ${ }^{7}$.

1. Instituto Tecnológico Regional Centro-Sur, Universidad Tecnológica, Durazno, Uruguai.

2. Instituto Federal Farroupilha, Campus de Alegrete, RS, Brasil. 
3. Universidade Federal do Pampa/Alegrete, RS, Brasil.

4. Programa de Pós-Graduação em Engenharia Agrícola, Universidade Federal de Santa Maria, Santa Maria, RS, Brasil.

5. Instituto Federal Catarinense - Campus Concórdia, SC, Brasil.

6. Instituto de Desenvolvimento Educacional do Alto Uruguai - Faculdade IDEAU, Campus Passo fundo, RS, Brasil.

7. Programa de Pós-graduação em Agronomia da Universidade Federal de Santa Maria, Santa Maria, RS, Brasil.

*Autor para correspondência: luishumbertoben@gmail.com 